\title{
Long-term cognitive, psychosocial,
} and neurovascular complications of unilateral head and neck irradiation in young to middle-aged adults

Judith T. Pruijssen ${ }^{1 *}{ }^{*}$, Ashwin Wenmakers ${ }^{2+}$, Roy P. C. Kessels ${ }^{3,4,5}$, Vitoria Piai ${ }^{6,4}$, Frederick J. A. Meijer ${ }^{7}$, Sjoert A. H. Pegge ${ }^{7}$, Jacqueline J. Loonen ${ }^{8}$, Anil M. Tuladhar ${ }^{9}$, Hendrik H. G. Hansen', Johannes H. A. M. Kaanders ${ }^{2}$ and Joyce Wilbers ${ }^{8}$

\begin{abstract}
Background: With a growing, younger population of head and neck cancer survivors, attention to long-term sideeffects of prior, often radiotherapeutic, treatment is warranted. Therefore, we studied the long-term cognitive effects in young adult patients irradiated for head and neck neoplasms (HNN).

Methods: Young to middle-aged adults with HNN (aged 18-40 years) and treated with unilateral neck irradiation $\geq 5$ years before inclusion underwent cardiovascular risk and neuropsychological assessments and answered validated questionnaires regarding subjective cognitive complaints, fatigue, depression, quality of life, and cancerspecific distress. Additionally, magnetic resonance imaging (MRI) of the brain was performed to assess white matter hyperintensities (WMH), infarctions, and atrophy.
\end{abstract}

Results: Twenty-nine patients (aged 24-61, 13 men) median 9.2 [7.3-12.9] years post-treatment were included. HNN patients performed worse in episodic memory (Z-score $=-1.16[-1.58-0.34], p<0.001)$ and reported more fatigue symptoms (Z-score $=1.75$ [1.21-2.00], $p<0.001)$ compared to normative data. Furthermore, patients had a high level of fear of tumor recurrence (13 patients [44.8\%]) and a heightened speech handicap index (13 patients [44.8\%]). Only a small number of neurovascular lesions were found (3 infarctions in 2 patients and 0.11 [0.00-0.40] mL WMH), unrelated to the irradiated side. Cognitive impairment was not associated with WMH, brain atrophy, fatigue, or subjective speech problems.

Conclusions: HNN patients showed impairments in episodic memory and an increased level of fatigue $\geq 5$ years after radiotherapy compared to normative data. Cognitive impairments could not be explained by WMH or brain atrophy on brain MRI or psychological factors.

Trial registration: Clinicaltrials.gov (https://clinicaltrials.gov/ct2/show/NCT04257968).

\footnotetext{
*Correspondence: Judith.pruijssen@radboudumc.nl

†Judith T. Pruijssen and Ashwin Wenmakers contributed equally.

1 Medical Ultrasound Imaging Center (MUSIC), Department of Medical

Imaging/Radiology, Radboud Institute Health Sciences, Radboud

University Medical Center, Geert Grooteplein Zuid 10, 6525 GA Nijmegen,

the Netherlands

Full list of author information is available at the end of the article
}

(C) The Author(s) 2022. Open Access This article is licensed under a Creative Commons Attribution 4.0 International License, which permits use, sharing, adaptation, distribution and reproduction in any medium or format, as long as you give appropriate credit to the original author(s) and the source, provide a link to the Creative Commons licence, and indicate if changes were made. The images or other third party material in this article are included in the article's Creative Commons licence, unless indicated otherwise in a credit line to the material. If material is not included in the article's Creative Commons licence and your intended use is not permitted by statutory regulation or exceeds the permitted use, you will need to obtain permission directly from the copyright holder. To view a copy of this licence, visit http://creativecommons.org/licenses/by/4.0/. The Creative Commons Public Domain Dedication waiver (http://creativeco mmons.org/publicdomain/zero/1.0/) applies to the data made available in this article, unless otherwise stated in a credit line to the data. 
Keywords: Head and neck cancer, Radiotherapy, Cognition, Fatigue, Quality of life

\section{Background}

Head and neck cancer (HNC) survival has increased over the past decades due to improved diagnostic and therapeutic modalities, such as modern diagnostic imaging, improved radiotherapy planning, and concurrent chemo-, immuno-, and radiotherapy [1-3]. A growing population of HNC survivors requires insight into long-term side-effects of prior radiotherapy $[4,5]$. Although neurocognitive side-effects in other cancer types such as breast, colorectal, and prostate cancer are well established [6], little is known about these sideeffects in HNC survivors.

$\mathrm{HNC}$ is a heterogeneous disease, including tumors of different histologies and at different sites such as carcinomas of the oral cavity, larynx, and (naso)pharynx but also salivary gland tumors. All these subtypes vary regarding treatment regimens and side-effects. However, cognitive decline within 2 years after treatment has been shown in various HNC populations in multiple small prospective studies, affecting memory, verbal fluency, motor function, and speed of information processing [7-14]. This cognitive decline seemed to persist $>5$ years after treatment [15-17]. Concerning subjective complaints, memory problems, fatigue, anxiety, reduced quality of life, and depressive symptoms are frequently reported in HNC survivors $[7,9,10,14$, 16-19].

Limited literature exists on the correlation of objective cognitive impairment in HNC survivors with subjective cognitive, physical, and psychological complaints and neurovascular abnormalities. We previously showed that lower cognitive performance correlated with subjective memory complaints and fatigue in HNC survivors $>5$ years after radiotherapy [17]. This emphasizes the importance to consider both endpoints.

Besides, most studies have been performed in older patients ( $>50$ years) with typical, lifestyle-induced HNC. As HNC and cognitive decline may have a common etiology, such as alcohol and tobacco use [20,21], the incidence and pathophysiology of cognitive impairment in a younger population with fewer comorbidities could differ. While research in non-HNC cancers showed that young cancer survivors may be more resilient to cognitive impairment [22], they are also in a life-stage in which they are highly active socially, professionally, and/or academically. This may explain why cognitive complaints and psychological distress are frequently reported by these patients [23]. With a rising incidence of HNC in a younger population related to the human papillomavirus
(HPV) epidemic [ 24], increased research and clinical attention to cognitive impairment in young survivors are needed.

Here, we aim to estimate the association of radiotherapy of the neck with long-term cognitive functioning, fatigue, depressive symptoms, and quality of life in a unique cohort of young to middle-aged adults treated with unilateral radiotherapy of the neck. Assuming that vascular changes underlie cognitive decline, the extent and aspect of white matter hyperintensities (WMH) were related to the irradiated side of the neck.

\section{Methods}

This study is a cross-sectional study designed to determine the long-term vascular and cognitive complications of radiotherapy of the neck in young to middle-aged adults. Participants were recruited from the Radboud university medical center, the Netherlands, and identified by querying unilateral radiotherapy of the neck between 2010 and 2015 in the radiotherapy database. Patients were eligible for inclusion when they had been treated with unilateral radiotherapy for a malignant or benign head and neck neoplasm $(\mathrm{HNN}) \geq 5$ years before inclusion. The carotid artery had to be, at least partly, in the radiotherapy target volume. Age at diagnosis had to be between 18 and 40. Exclusion criteria were contraindications to magnetic resonance imaging (MRI) and insufficient command of the Dutch language. This study was performed in line with the principles of the 1964 Declaration of Helsinki. The study was approved by the Medical Ethics Review Committee Arnhem-Nijmegen (NL71550.091.19) on November 25, 2019, and registered at clinicaltrials.gov (NCT04257968). All participants provided written informed consent.

\section{Radiation treatment}

Before this study, all patients had been treated with external beam radiotherapy with a total dose of 26-100 Gy in 2-Gy fractions. Radiotherapy was applied with a linear accelerator (6-MV photon beams) using a three-dimensional conformal or intensity-modulated radiotherapy technique. Radiotherapy targets were defined by computed tomography and included the primary tumor site, usually the parotid gland or unilateral oropharynx, with or without the ipsilateral neck. Nobody received wholebrain radiotherapy. 


\section{Cardiovascular risk profile}

Patients were invited to the outpatient clinic of the Radboudumc Center of Expertise for Cancer Survivorship. There, a structured cardiovascular disease (CVD) risk profile was assessed based on the European guidelines on cardiovascular disease prevention [25], including the following risk factors: I) Smoking: current/former, expressed in pack-years; II) Family history of CVD: firstdegree males $\leq 55$ years or females $\leq 65$ years with CVD; III) Hypertension: systolic blood pressure $>140 \mathrm{mmHg}$ or antihypertensive medication use; IV) Diabetes mellitus: non-fasting serum glucose $>11.1 \mathrm{mmol} / \mathrm{L}$ or antidiabetic drug use; V) Hypercholesterolemia: serum low-density lipoprotein $\geq 2.6 \mathrm{mmol} / \mathrm{L}$ and/or non-high-density lipoprotein $\geq 3.4 \mathrm{mmol} / \mathrm{L} ; \mathrm{VI}$ ) Overweight: body mass index $\geq 25$ and/or abdominal circumference $\geq 88 \mathrm{~cm}$ for women or $\geq 102 \mathrm{~cm}$ for men; VII) Chronic daily stress: daily stress $>6$ months (work, private, etcetera); and VIII) Chronic renal insufficiency: CKD-EGFR $<90 \mathrm{ml} /$ $\mathrm{min} / 1.73 \mathrm{~m} 2$ and/or albumin-to-creatinine ratio $>3$.

\section{Neuropsychological assessment (NPA)}

Education level was classified using seven categories based on the Dutch educational system, ranging from one (less than primary school) to seven (academic degree) [26]. NPAs were carried out by a trained examiner and consisted of validated, widely used tests to determine each individual's performance in five cognitive domains: I) Episodic Memory (anterograde verbal memory), assessed by the total number correct (trials 1 to 3 ) and the delayed recall score of the Hopkins Verbal Learning Test [27]; II) Working Memory, measured by the backward and forward Digit Span test [28]; III) Executive Functioning, indexed by the Trail Making Test $\mathrm{B} / \mathrm{A}$ ratio score [29], the Brixton Spatial Anticipation Test [30], and the Interference score of the Stroop Color-Word Test [31]; IV) Verbal Fluency (letter/category fluency) [32]; and V) Speed of Information Processing, based on the Stroop test (parts I and II) [31], Trail Making Test A [29], and Symbol Digit Substitution Test [33]. A more elaborate overview of the cognitive domain tests is provided in Appendix 1.

\section{Psychological questionnaires}

Psychological symptoms were assessed using the Brief Symptom Inventory (BSI), measuring emotional distress on different dimensions including somatization, depression, and anxiety [34]. Fear of cancer recurrence and its impact on daily life were assessed using the Cancer Worry Scale (CWS) [35]. A severe level of fear of recurrence is identified by a score $\geq 14$ [35]. Subjective memory complaints were assessed with the Cognitive
Failure Questionnaire (CFQ) [36]. Fear and depressive symptoms were assessed using the Hospital Anxiety and Depression Scale (HADS) [37]. A score $\geq 11$ on the depression or anxiety subscales is classified as abnormal [37]. Fatigue was assessed using the Checklist Individual Strength (CIS-20R) [38]. A score $\geq 35$ on the CIS-20R Fatigue subscale indicates a heightened experience of fatigue [39]. Cancer-specific distress was assessed using the Impact of Event Scale-Revised [40]. Self-perceived speech function was assessed using the Speech Handicap Index (SHI) [41], differentiating speech function from psychosocial functioning. A score $\geq 6$ identifies patients with speech problems in daily life [41]. Quality of life was assessed using the European Organization for Research and Treatment for Cancer Quality of Life Questionnaire (EORTC-QLQ-C30) [42] with functional, symptom, and global subscales.

\section{Brain MRI}

Brain MRIs were acquired using a 3.0 Tesla MR-system (Skyra, Siemens Erlangen). The scan protocol included three-dimensional $\mathrm{T} 1$ magnetization-prepared rapid acquisition gradient echo (3DT1-MPRAGE), T2 turbo spin-echo (T2-TSE), and 3D fluid-attenuated inversion recovery (3DT2-FLAIR) brain sequences. Scan parameters included: 3DT1-MPRAGE) repetition time (TR)/echo time (TE) 2300/2.32 ms, inversion time (TI) $900 \mathrm{~ms}$, slice thickness $0.9 \mathrm{~mm}$, flip angle $8^{\circ}$, voxel size $0.9 \times 0.9 \times 0.9 \mathrm{~mm}^{3}$; T2-TSE) TR/TE $3500 / 92 \mathrm{~ms}$, slice thickness $5 \mathrm{~mm}$, flip angle $120^{\circ}$, voxel size $0.5 \times 0.5 \times 5$ $\mathrm{mm}^{3}$; 3DT2-FLAIR) TR/TE 5000/394 ms, TI $1800 \mathrm{~ms}$, slice thickness $1 \mathrm{~mm}$, voxel size $0.5 \times 0.5 \times 1 \mathrm{~mm}^{3}$. Two experienced neuroradiologists rated brain infarctions and vascular WMH using the Fazekas scale [43]. Complementary, WMH were manually segmented on the FLAIR sequence images using Pinnacle treatment planning software (Philips Radiation Oncology Systems, Fitchburg, WI, USA) to assess WMH volumes in the irradiated and non-irradiated side. T1- and T2-weighted image sequences were used to identify WMH based on the STandards for ReportIng Vascular changes on $\mathrm{nEu}-$ roimaging [44]. A previously published Brain Extraction Tool [45] was applied to automatically segment the T1-weighted images into brain and non-brain structures. Brain structures were subsequently segmented into grey matter (GM), white matter (WM), and cerebrospinal fluid (CSF) using the FMRIB's Automated Segmentation Tool [46]. Tissue volumes were calculated by summing all voxel volumes belonging to that tissue type. The brain parenchymal fraction (BPF), as a measure of brain atrophy, was calculated as (volume GM+WM)/(volume $\mathrm{WM}+\mathrm{GM}+\mathrm{CSF}$ ) [47]. 


\section{Statistical analysis}

Cognitive performance and questionnaire scores for each individual were adjusted for age, sex, and education level using available Dutch normative data and converted into standardized Z-scores. Composite scores per cognitive domain were calculated as the average of the Z-scores of the associated subtests (in case of more than one outcome measure). A composite Z-score $\leq-1.65$ (i.e. $\leq 5^{\text {th }}$ percentile) was classified as clinically impaired [48]. The number of patients with a composite score $\leq-1.65$ or, if existing, exceeding a pre-specified cut-off value (for the psychological questionnaires) per cognitive domain and questionnaire were quantified.

Given the relatively small sample, data were expressed using the median and interquartile range (IQR) and statistical analysis was performed using non-parametric tests. One-sample Wilcoxon signed-rank tests were used to compare median Z-scores per cognitive domain and total Z-scores per questionnaire with the normative standardized median $(Z=0)$. In case the Wilcoxon signed-rank test was statistically significant for the total questionnaire score, individual questionnaire domains were tested accordingly. To assess the pathophysiological mechanism underlying cognitive impairments, MRI results and psychological questionnaires substantially differing from the normative mean were compared between patients with an impairment $(Z$-score $\leq-1.65)$ in $\geq 1$ cognitive domain and those without such impairment using Mann-Whitney $U$ tests. Analyses were corrected for multiple comparisons by the BenjaminiHochberg method [49] with a false discovery rate of 0.05 . Non-adjusted p-values are reported.

\section{Results}

Twenty-nine HNN patients were enrolled in this study. A flowchart of the patient inclusion is shown in Fig. 1. Ten additional eligible patients were excluded due to reasons stated in Fig. 1. All patients fulfilled the study protocol, except for one patient who refused a brain MRI. Patient characteristics are summarized in Table 1. Median age at inclusion was 41.0 [IQR: 33.5-47.0] years. Median follow-up after radiotherapy was 9.2 [7.3-12.9] years. One patient received a re-irradiation for a recurrence of the primary tumor resulting in a maximum physical dose of $100 \mathrm{~Gy}$. Ten patients (34.5\%) received concomitant chemotherapy. Five patients (17.2\%) underwent extensive surgical interventions of the head and neck including a tongue (edge) resection, hemi-mandibulectomy, or cheek resection. Most patients $(89.7 \%)$ had at least one CVD risk factor, including mostly hypercholesterolemia, chronic daily stress, and overweight. Cholesterol levels and renal function were unknown in 6 and 3 patients, respectively.

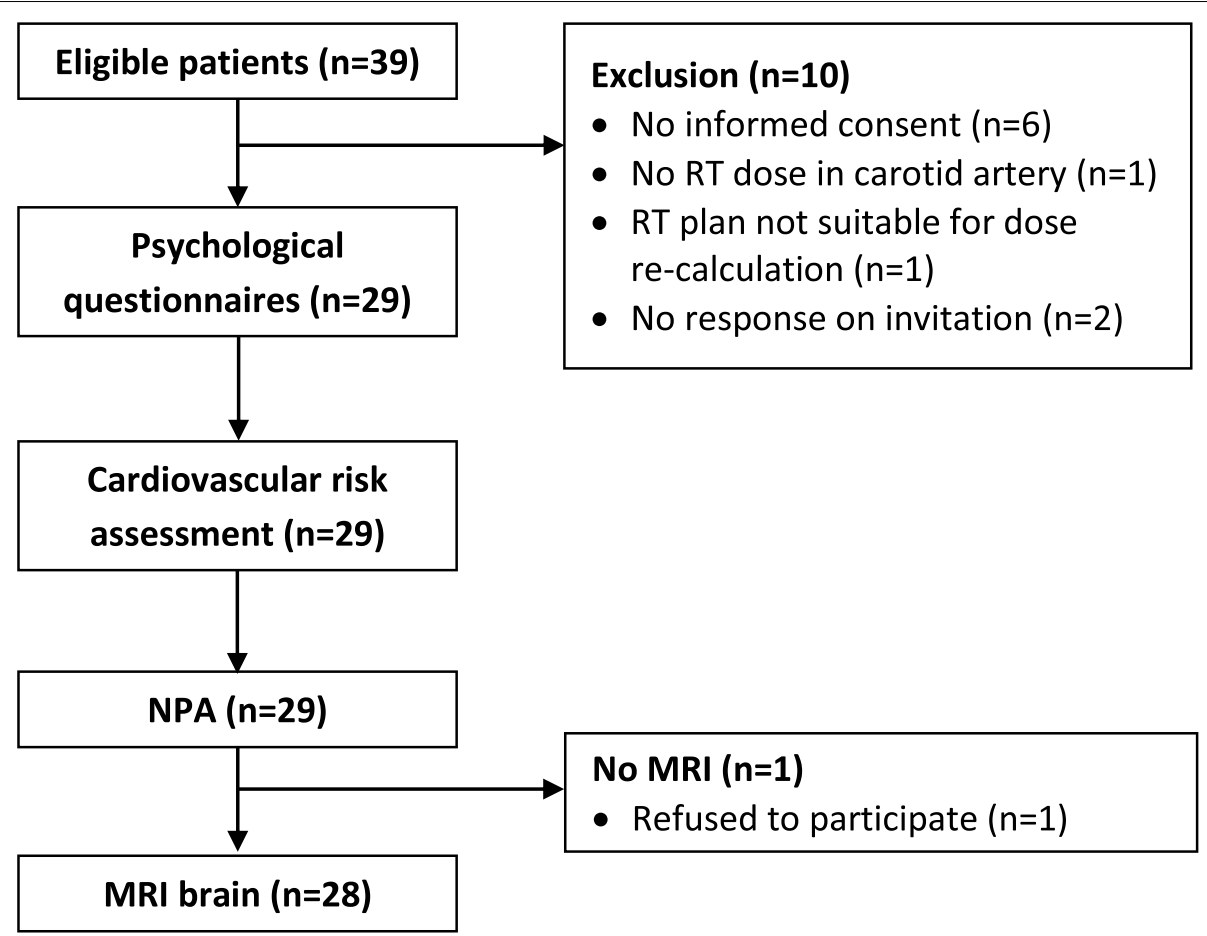

Fig. 1 Flow-chart of patient inclusion. $N P A=$ neuropsychological assessment, $R T=$ radiotherapy, $M R I=$ magnetic resonance imaging 
Table 1 Patient characteristics

\begin{tabular}{|c|c|}
\hline Characteristic & $n=29$ \\
\hline \multicolumn{2}{|l|}{ Demographics } \\
\hline Men, n (\%) & $13(44.8)$ \\
\hline Median age, years [IQR] & $41.0[33.5-47.0]$ \\
\hline Median age at treatment, years [IQR] & $35.0[23.5-39.5]$ \\
\hline Median follow-up after RT, years [IQR] & $9.2[7.3-12.9]$ \\
\hline \multicolumn{2}{|l|}{ Diagnosis, n (\%) } \\
\hline Carcinoma of parotid & $7(24.1)$ \\
\hline Pleiomorphic adenoma of parotid & $8(27.5)$ \\
\hline Carcinoma of oropharynx & $2(6.9)$ \\
\hline Lymphoma (primary) & $8(27.6)$ \\
\hline Others $^{\mathrm{a}}$ & $4(13.8)$ \\
\hline \multicolumn{2}{|l|}{ Radiotherapy } \\
\hline Total dose, Gy (median [IQR], min-max) & $50[37.0-66.0], 26-100^{b}$ \\
\hline \multicolumn{2}{|l|}{ Chemotherapy, n (\%) } \\
\hline Total & $10(34.5)$ \\
\hline Anthracycline & $9(31.0)$ \\
\hline Platinum-based & $2(6.9)$ \\
\hline Alkylating & $8(27.5)$ \\
\hline Others & $8(27.5)$ \\
\hline \multicolumn{2}{|l|}{ Surgery } \\
\hline (Partial) parotidectomy & $16(55.2)$ \\
\hline Cervical lymph node dissection & $5(17.2)$ \\
\hline Resection tongue(edge) & $2(6.9)$ \\
\hline (Hemi)mandibulectomy & $2(6.9)$ \\
\hline Others & $4(13.8)$ \\
\hline \multicolumn{2}{|l|}{ Tumor laterality, $\mathrm{n}(\%)$} \\
\hline Left & $18(62.1)$ \\
\hline Right & $11(37.9)$ \\
\hline \multicolumn{2}{|l|}{ CVD risk factors, $\mathrm{n}(\%)$} \\
\hline \multicolumn{2}{|l|}{ Smoking } \\
\hline Current & $6(20.7)$ \\
\hline Former & $5(17.2)$ \\
\hline Pack years, median [IQR] & $15.0[5.0-25.0]$ \\
\hline Positive family history of CVD & $8(27.6)$ \\
\hline Chronic daily stress & $10(34.5)$ \\
\hline Hypertension & $8(27.6)$ \\
\hline Hypercholesterolemia & $10(43.5)$ \\
\hline Overweight & $12(41.4)$ \\
\hline Diabetes & $1(3.4)$ \\
\hline Chronic renal insufficiency & $3(11.5)$ \\
\hline \multicolumn{2}{|l|}{ Number of CVD risk factors, $\mathrm{n}(\%)$} \\
\hline 0 & $3(10.3)$ \\
\hline 1 & $6(20.7)$ \\
\hline 2 & $11(37.9)$ \\
\hline$\geq 3$ & $9(31.0)$ \\
\hline Education level, median [IQR] & $6.0[5.0-7.0]$ \\
\hline \multicolumn{2}{|l|}{ Manual laterality } \\
\hline Right & $23(79.3)$ \\
\hline Left & $5(17.2)$ \\
\hline Bimanual & $1(3.4)$ \\
\hline
\end{tabular}

a i.e. multiple glomus tumors, supraclavicular epithelioid hemangioendothelioma, mucoepidermoid carcinoma accessory salivary gland, and submandibular squamous cell carcinoma. ${ }^{\mathrm{b}}$ One patient underwent a re-irradiation for recurrence of the primary tumor resulting in a total radiation dose of $100 \mathrm{~Gy}$. CVD Cardiovascular disease

\section{Neuropsychological assessment}

The neuropsychological assessment revealed a statistically significantly worse episodic-memory performance compared to normative data (Z-score $=-1.16[-1.58-$ $0.34], p<0.001$ ) (Table 2).

\section{Psychological questionnaires}

Forty-five percent of patients reported a severe level of fear of tumor recurrence (CWS-score $\geq 14$ ) (Table 3). Furthermore, fatigue was highly prevalent: $51.7 \%$ experienced severe fatigue (subjective fatigue score $\geq 35$ ) and Z-scores were statistically significant higher in all fatigue dimensions compared to normative data $(p<0.001)$. Additionally, $44.8 \%$ of patients reported speech problems in daily life (SHI-score $\geq 6$ ). All other questionnaires did not differ from normative means.

\section{Brain MRI}

The twenty-eight brain MRIs showed 3 brain infarctions in 2 patients (bilaterally in one patient and ipsilateral to the irradiated side in the other patient). WMH were classified as Fazekas 0 and 1 in $10(35.7 \%)$ and 18 patients (64.2\%), respectively. No patients had Fazekas 2-3 WMH. Total volume of WMH was 0.11 [0.00-0.40] $\mathrm{mL}$, unrelated to radiation side (irradiated side: $0.05[0.00-0.19]$ $\mathrm{mL}$, control side: $0.03[0.00-0.26] \mathrm{mL}, p=0.62)$. Median $\mathrm{BPF}$, as a measure of brain atrophy, was 0.78 [0.77-0.79].

\section{Association cognitive performance, fatigue, speech problems, WMH, and brain atrophy}

Patients with an impairment in $\geq 1$ cognitive domain did not show statistically significant differences in fatigue severity, speech handicap index, WMH volume, or brain atrophy compared to patients without cognitive impairment (Table 4).

\section{Discussion}

In this cross-sectional study, a unique cohort of twentynine young to middle-aged adult HNN survivors was included with median 9 years of follow-up after unilateral radiation of the neck. To assess long-term cognitive and psychological side-effects of HNN treatment, all patients underwent a neuropsychological assessment, completed psychological questionnaires, and had a brain MRI. HNN patients had an impaired episodic memory compared to normative data. This impairment was not associated with WMH, brain atrophy, fatigue, or self-perceived speech problems. Besides, patients reported more fatigue, fear of tumor recurrence, and speech problems compared to normative data.

With a growing, younger population of HNC survivors, partly due to the HPV epidemic, attention and prevention of long-term cognitive side-effects of treatment 
Table 2 Results cognitive domain data

\begin{tabular}{|c|c|c|c|}
\hline Characteristic & Median $[\mathrm{IQR}]^{\mathrm{a}}$ & $P$-value ${ }^{b}$ & Impaired, $\mathrm{n}(\%)^{\mathrm{d}}$ \\
\hline Episodic memory & $-1.16[-1.58-0.34]$ & $<0.001^{c}$ & $5(17.2)$ \\
\hline Working memory & $-0.00[-0.67-0.84]$ & 0.76 & $4(13.8)$ \\
\hline Executive functioning & $-0.01[-0.26-0.42]$ & 0.72 & $0(0.0)$ \\
\hline Verbal fluency & $0.25[-0.30-1.05]$ & 0.07 & $0(0.0)$ \\
\hline Speed of information processing & $-0.27[-1.22-0.43]$ & 0.14 & $4(13.8)$ \\
\hline
\end{tabular}

${ }^{a}$ Data of composed Z-scores are expressed as median [interquartile range] based on normative data with a mean Z-score of zero; ${ }^{\mathrm{b}}$ Not Benjamini-Hochberg adjusted p-values are shown; ${ }^{c}$ Statistically significant change compared to normative data after Benjamini-Hochberg correction; ${ }^{d}$ Impaired composed Z-score is defined as $Z \leq-1.65$ (performance worse than $95 \%$ of the norm population)

become increasingly important. Only limited data are available on the long-term side-effects. Most prior studies are limited to older, typical HNC patients. As a result, evidence-based personalized screening and prevention guidelines for long-term complications are lacking in clinical practice.

The memory impairment in our sample of HNN survivors many years after radiotherapy is in concordance with previous studies in $\mathrm{HNC}$ on short-term ( $<2$ years) [7, 9-14] and long-term ( $\geq 5$ years) sequelae after treatment $[14,15]$. Although previous studies also found a decreased speed of information processing, we only found a trend in this direction in HNN patients. This discrepancy may be due to the small number of patients or younger age of our study cohort with less cardiovascular risk factors (by themselves related to cognitive decline [50]) if compared to older, more typical HNC survivors. Multiple studies in hematologic, breast, and ovarian cancers showed that older age was associated with cognitive impairment after treatment [51]. Younger survivors may be more resilient to cognitive impairment due to a greater cognitive reserve [52], i.e. an individual's ability to compensate for brain pathology [53]. This greater cognitive reserve in young patients may be related to higher neuroplasticity, i.e. the ability to form neural connections enabling compensatory pathways [22]. This high neuroplasticity leads to maintained neurocognitive performance and recovery from cognitive impairment [52].

The pathophysiological mechanism underlying cognitive impairment in HNC patients is not completely understood. Radiation to the carotid artery is thought to accelerate carotid atherosclerosis due to radiationinduced endothelial cell damage, fibrosis of the intimamedial layer, development of atherosclerotic plaques, and occlusion of the vasa vasorum leading to arterial wall ischemia [54]. Radiation-induced carotid vasculopathy, i.e. increased intima-media thickness and carotid artery stenosis has been shown in previous studies [55, 56]. Cerebrovascular lesions such as WMH [57] secondary to carotid vasculopathy [57] are associated with progressive cognitive decline and a two-fold dementia risk $[58,59]$ and are thought to underly cognitive impairment after neck irradiation. This is, in contrast to (scattered) radiation to the brain, an indirect effect. In the context of another study [submitted for publication], all patients included in this study underwent a bilateral carotid ultrasound. Ten patients (34\%) had (a) carotid plaque(s), i.e. an intima-media thickness $\geq 1.5 \mathrm{~mm}$, but they were not hemodynamically significant (stenosis percentage $<50 \%$ ) and showed no signs of instability. These results, together with the low number of neurovascular lesions, make it unlikely that carotid pathology underlies the cognitive impairment found in the current study. However, also direct effects of radiotherapy to the brain have been reported in for example nasopharyngeal tumor patients [10] and cannot be excluded in the current study. Patients treated with radiotherapy for parotid gland tumors or high metastatic lymph nodes in the neck may have had low radiation doses to the ipsilateral temporal lobe or cerebellum, respectively. Although these effects are likely to be limited as radiation doses were low and direct effects are dose-dependent [10], some effect of this cannot be excluded. However, radiation doses to the frontal and parietal regions of the brain are negligible in our patient population.

Unique in this study was the comparison in neurovascular abnormalities between the radiated and non-irradiated vascular brain territory, excluding the influence of confounding factors. To our knowledge, only we have previously studied the relation between WMH and cognitive impairment in long-term HNC survivors [17]. In concordance with our previous findings, WMH were currently not associated with cognitive impairment. Cognitive scores were also not related to tumor laterality or to tumor laterality relative to manual laterality. However, we previously found an association between brain infarctions and cognitive impairment that was absent in the current study. The two patients with brain infarctions in the current study reported severe fatigue $(Z$-score $=2.05-2.84$ ) but did not have any other cognitive or psychological 
Table 3 Results psychological questionnaires

\begin{tabular}{|c|c|c|c|}
\hline Characteristic & 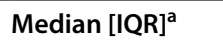 & $P$-value ${ }^{b}$ & $N(\%)$ impaired $^{d}$ \\
\hline \multicolumn{4}{|l|}{ BSI } \\
\hline Depression & $-0.39[-0.79-0.41]$ & & $4(13.8)$ \\
\hline Somatization & $-0.72[-0.83-0.39]$ & & $4(13.8)$ \\
\hline Fear & $-0.69[-0.80-0.16]$ & & $5(17.2)$ \\
\hline Total & $-0.64[-0.86-0.32]$ & 0.28 & $5(17.2)$ \\
\hline CWS & $-0.10[-0.87-0.67]$ & 0.91 & $13(44.8)^{\mathrm{e}}$ \\
\hline \multicolumn{4}{|l|}{ CFQ } \\
\hline $\begin{array}{l}\text { Absentminded- } \\
\text { ness }\end{array}$ & $-0.32[-1.27-1.15]$ & & $3(10.3)$ \\
\hline Social & $-0.38[-1.63-0.54]$ & & $1(3.4)$ \\
\hline Names & $0.05[-0.76-1.00]$ & & $2(6.9)$ \\
\hline Orientation & $-0.61[-1.63-0.21]$ & & $4(13.8)$ \\
\hline Total & $-0.25[-1.53-0.96]$ & 0.24 & $3(10.3)$ \\
\hline \multicolumn{4}{|l|}{ HADS } \\
\hline Depression & $0.18[-0.73-0.79]$ & & $2(6.9)^{e}$ \\
\hline Anxiety & $-0.86[-1.14-0.03]$ & & $3(10.3)^{e}$ \\
\hline Total & $-0.22[-0.86-0.26]$ & 0.26 & $3(10.3)$ \\
\hline \multicolumn{4}{|l|}{ CIS-20R } \\
\hline Fatigue severity & $1.75[1.21-2.00]$ & $<0.001^{c}$ & $15(51.7)^{\mathrm{e}}$ \\
\hline $\begin{array}{l}\text { Concentration } \\
\text { problems }\end{array}$ & $2.30[1.70-2.60]$ & $<0.001^{c}$ & $25(86.2)$ \\
\hline $\begin{array}{l}\text { Reduced motiva- } \\
\text { tion }\end{array}$ & $1.24[0.76-1.98]$ & $<0.001^{c}$ & $9(31.0)$ \\
\hline Activity & 1.64 [1.09-1.98] & $<0.001^{c}$ & $14(48.3)$ \\
\hline Total & $1.94[1.74-2.30]$ & $<0.001^{c}$ & $23(79.3)$ \\
\hline \multicolumn{4}{|l|}{ Impact of Event Scale } \\
\hline Reliving & $-0.33[-0.55-0.05]$ & & $0(0.0)$ \\
\hline Avoidance & $0.05[0.05-0.59]$ & & $4(13.8)$ \\
\hline Total & $-0.18[-0.31-0.39]$ & 0.96 & $1(3.4)$ \\
\hline \multicolumn{4}{|l|}{ SHI } \\
\hline $\begin{array}{l}\text { Psychosocial } \\
\text { function }\end{array}$ & $-0.24[-0.24-1.87]$ & & $7(24.1)$ \\
\hline Speech function & $-0.19[-0.50-3.53]$ & 0.03 & $12(41.4)$ \\
\hline Total & $-0.23[-0.43-3.19]$ & & $13(44.8)^{\mathrm{e}}$ \\
\hline \multicolumn{4}{|l|}{ EORTC QLQ C30 } \\
\hline \multicolumn{4}{|l|}{ - Functional scales } \\
\hline Physical & $0.57[-0.46-0.65]$ & & $2(6.9)$ \\
\hline Role & $0.50[-0.92-0.59]$ & & $2(6.9)$ \\
\hline Emotional & $0.04[-0.76-0.60]$ & & $3(10.3)$ \\
\hline Cognitive & $0.50[-1.58-0.50]$ & & $5(17.2)$ \\
\hline Social & $0.36[-0.69-0.39]$ & & $3(10.3)$ \\
\hline Total & $-0.02[-0.70-0.51]$ & 0.55 & $2(6.9)$ \\
\hline \multicolumn{4}{|l|}{ - Symptom scales } \\
\hline Fatigue & $0.11[-0.79-1.16]$ & & $5(17.2)$ \\
\hline Nausea & $-0.30[-0.30-0.25]$ & & $0(0.0)$ \\
\hline Pain & $-0.60[-0.75-0.64]$ & & $4(13.8)$ \\
\hline Dyspnea & $-0.42[-0.42-0.39]$ & & $2(6.9)$ \\
\hline Sleeplessness & $-0.55[-0.65-0.63]$ & & $3(10.3)$ \\
\hline Eating & $-0.31[-0.31-0.23]$ & & $4(13.8)$ \\
\hline Constipation & $-0.28[-0.38-0.28]$ & & $2(6.9)$ \\
\hline Diarrhea & $-0.27[-0.32-0.27]$ & & $3(10.3)$ \\
\hline
\end{tabular}

Table 3 (continued)

\begin{tabular}{clll}
\hline Characteristic & Median $\left[\right.$ IQR $^{\mathbf{a}}$ & $\boldsymbol{P}_{\text {-value }}^{\mathbf{b}}$ & $\mathbf{N}(\%)$ impaired $^{\mathbf{d}}$ \\
\hline Financial & $-0.28[-0.28-0.23]$ & $2(6.9)$ \\
Total & $-0.10[-0.36-0.25]$ & 0.60 & $1(3.4)$ \\
- Global & $0.35[-0.11-1.05]$ & 0.07 & $2(6.9)$
\end{tabular}

${ }^{a}$ Data are expressed as median [interquartile-range] based on normative data with a mean Z-score of zero. Impaired Z-score is defined as $Z \leq-1.65$ (performance worse than $95 \%$ of the norm population); ${ }^{\mathrm{b}}$ Not BenjaminiHochberg adjusted $p$-values are shown; ' Statistically significant change compared to normative data after Benjamini-Hochberg correction; ${ }^{d}$ based on Z-score $>1.65$ or, if marked with ${ }^{\mathrm{e}}$, on a predefined clinical cut-off value (i.e. BSI-total: $\geq 14$, HADS-depression $\geq 11$, HADS-anxiety $\geq 11, \mathrm{CIS}-20 \mathrm{R}$ fatigue severity $\geq 35$, and SHI-total $\geq 6$ ). BSI Brief Symptom Inventory, CWS Cancer Worry Scale, CFQ Cognitive Failure Questionnaire, HADS Hospital Anxiety and Depression Scale CIS-20R Checklist Individual Strength-20R, SHI Speech Handicap Index, EORTC QLQ C30 European Organization for Research and Treatment for Cancer Quality of Life Questionnaire

impairments. Cognitive decline in HNC patients has furthermore been associated with fatigue, fear, depressive symptoms, and self-perceived speech problems $[14$, $17,60]$. However, we currently did not find such association. These discrepancies may be explained by different aspects of brain infarctions, e.g. localization, size, and time-since brain infarction. Alternatively, there is a common etiology of $\mathrm{HNC}$ and cognitive decline in older age, such as alcohol and tobacco use, that are less common in our study cohort. A different pathophysiological mechanism underlying cognitive decline in younger patients would entail alternative prevention strategies in this population.

A growing and younger population of $\mathrm{HNC}$ survivors also asks for adjustments of screening and prevention methods to age-specific psychosocial complaints. Fatigue is reported in one-fourth of young adult cancer survivors 5-30 years after treatment [61]. An even higher prevalence (up to $79 \%$ ) was also found $\geq 5$ years after treatment in older, typical HNC patients [17]. Despite its high prevalence, this symptom is underrecognized and often left untreated [62]. Fatigue may negatively influence work, social relationships, mood, daily activities, and quality of life [63]. With work and a career at stake, fatigue may have an even higher impact on younger HNC survivors. Attention to the presence and possible treatment of fatigue is, therefore, necessary in this population.

Besides fatigue, fear of cancer recurrence is one of the most important late effects in HNC survivors [64]. While the likelihood of recurrence is highest within two years after diagnosis [65], the intensity of fear of recurrence does not significantly change over time $[66,67]$. High fear of tumor recurrence is reported in $31-52 \%$ of patients 1-20 years after treatment amongst different cancer types [35, 68-70]. Although not all tumors in our cohort were malignant, we found a comparable high rate 
Table 4 Association of cognitive impairment with fatigue, speech problems, vascular white matter hyper-intensities, and brain parenchymal fraction

\begin{tabular}{llll}
\hline Characteristic & $\begin{array}{l}\text { Cognitive impairment }(\boldsymbol{n}=10), \text { median } \\
{[\mathrm{IQR}]}\end{array}$ & $\begin{array}{l}\text { No cognitive impairment }(\boldsymbol{n}=\mathbf{1 9}), \\
\text { median [IQR] }\end{array}$ & $\begin{array}{l}\text { P-value } \\
\text { a }\end{array}$ \\
\hline Fatigue (CIS-20R, Z-score) & $1.74[1.50-2.43]$ & $1.99[1.79-2.25]$ & 0.70 \\
Speech problems (SHI, Z-score) & $1.59[-0.43-4.20]$ & $-0.43[-0.43-2.39]$ & 0.13 \\
WMH, mL & $0.15[0.00-0.39]$ & $0.09[0.00-0.51]$ & 0.70 \\
BPF & $0.79[0.77-0.79]$ & $0.78[0.77-0.78]$ & 0.21 \\
\hline
\end{tabular}

${ }^{a}$ Not Benjamini-Hochberg adjusted p-values are shown. CIS-20R Checklist Individual Strength-20R, SHI Speech Handicap Index, WMH white matter hyperintensities, $B P F$ brain parenchymal fraction

of fear of recurrence of $44.8 \%$. Psychological interventions including (contemporary) behavioral therapy have shown to be effective in sustainably reducing this fear and, therefore, should be considered in this population.

Speech problems can be differentiated in speech function (e.g. articulation problems due to anatomicalphysiological dysfunction resulting from surgery or radiotherapy) and psychosocial function (e.g. shame of speech function). Due to the different tumor nature and treatment in $\mathrm{HNN}$ patients compared to HNC patients with lower radiotherapy doses, less mutilating surgeries (mostly parotidectomies), and less tumor involvement of the larynx, our cohort cannot be compared to HNC patients. Besides the abovementioned speech problems, it is also important to account for communication problems due to speech formulation and perception (e.g. word-finding difficulties due to cognitive impairment resulting from neurovascular damage) that are currently not incorporated in screening tools.

Despite the memory impairment, patients did not report cognitive complaints. Multiple studies showed that patients' subjective cognitive symptoms do not correlate with objective cognitive function [71, 72]. Additionally, QoL was relatively unaffected in HNN patients despite the high prevalence of fatigue, fear of tumor recurrence, and self-reported speech problems. In other words, psychosocial complaints minimally affect daily life in these patients. This is consistent with other studies in long-term HNC survivors [17, 73, 74]. QoL is typically most affected shortly after diagnosis but returns to baseline values $48-72$ months after treatment [75]. This is presumably due to a change in internal standards, values, and priorities of patients over time, known as 'response shift' [76].

Some limitations of our study must be taken into consideration when interpreting the results. The small sample limits statistical analysis and inferences as possible confounders, such as cardiovascular disease, alcohol use, concomitant treatment (among others surgical intervention and chemotherapeutic treatment), and time-since-treatment could not be corrected for. These concomitant treatments are, however, known to affect cognitive performance in HNC patients [7, 8, 11, 77]. Furthermore, pre-treatment cognitive and psychosocial functioning were not assessed, while a decreased cognitive performance has been reported before treatment in HNC patients [60,78, 79]. The lack of a control group to assess cognitive impairment could have induced false positive results to assess cognitive impairment [77]. A large prospective, longitudinal study including a control group not exposed to radiotherapy but otherwise treated similarly with similar demographic and socioeconomic status assessing pre- and posttreatment cognitive performance, and considering the time-since-treatment, would be valuable for future studies. With the inclusion of unilateral irradiated HNN patients, we could compare neurovascular abnormalities, related to cognitive impairment, in the radiated and non-irradiated vascular brain territory unaffected by possible confounding factors. However, we did not find such asymmetry. Further studies with an even longer follow-up and higher radiation doses are warranted to verify this lack of asymmetry. Additionally, the current study only focused on structural neuroimaging (WMH and infarctions). More advanced neuroimaging techniques, including diffusion-weighted imaging, susceptibility-weighted imaging, and functional MRI would be valuable to detect microstructural damage. Diffusion-weighted imaging is sensitive to white matter damage in both WMH and normal-appearing white matter [80], and diffusion tensor imaging measures have been shown to correlate more strongly with cognitive impairment than WMH [81]. In contrast to previous studies in HNC patients, we also included patients with benign HNN with possibly fewer side-effects as only including HNC patients would have resulted in a very small sample. Furthermore, patients were partly included during the COVID-19 pandemic which may have influenced patients' psychosocial functioning, but this influence remains to be assessed. 


\section{Conclusions}

In conclusion, we evaluated long-term cognitive and psychological side-effects of head and neck radiotherapy in young to middle-aged adults. HNN patients had an episodic memory impairment that was not associated with WMH, brain atrophy, fatigue, or self-perceived speech problems. Moreover, HNN patients reported severe fatigue compared to normative data and had a high level of fear of tumor recurrence and subjective speech problems. Attention, prevention, and possible early treatment of long-term cognitive and psychosocial side-effects are warranted in HNC patients.

\begin{abstract}
Abbreviations
BPF: Brain parenchymal fraction; BSI: Brief Symptom Inventory; CFQ: Cognitive Failure Questionnaire; CIS-20R: Checklist Individual Strength; CSF: Cerebrospinal fluid; CVD: Cardiovascular disease; CWS: Cancer Worry Scale; 3DT1MPRAGE: Three-dimensional T1 magnetization-prepared rapid acquisition gradient-echo; 3DT2-FLAIR: Three-dimensional T2 fluid-attenuated inversion recovery; EORTC-QLQ-C30: European Organization for Research and Treatment for Cancer Quality of Life Questionnaire; GM: Gray matter; HADS: Hospital Anxiety and Depression Scale; HNC: Head and neck cancer; HNN: Head and neck neoplasms; HPV: Human papillomavirus; IQR: Interquartile range; MRI: Magnetic resonance imaging; NPA: Neuropsychological assessment; SHI: Speech Handicap Index; T2-TSE: T2 turbo spin-echo; TE: Echo time; TI: Inversion time; TR: Repetition Time; WM: White matter; WMH: White matter hyperintensities.
\end{abstract}

\section{Supplementary Information}

The online version contains supplementary material available at https://doi. org/10.1186/s12885-022-09295-9.

Additional file 1: Appendix 1. Cognitive domains with corresponding subtests of the neuropsychological assessment

\section{Acknowledgements}

The authors want to thank all patients for participating in this study, E.H.J. van Kampen for executing the neuropsychological assessments, I. KlabbersHelsper for her contribution to the data analysis, and K.H.P. Theijssen for her support in study management and planning.

\section{Authors' contributions}

Conceptualization: JP, JK and JW; Data curation: JP, AW, and JW; Formal analysis: JP, AW, RK, VP, AT, JK, and JW; Funding acquisition: JW; Investigation: JP, AW, FM, SP, and JW; Methodology: JP, JK, and JW; Project administration: JP and AW; Resources: JW; Supervision: JK and JW; Validation: JP, JK, and JW; Visualization: JP; Writing - original draft: JP and AW; Writing - review \& editing: JP, RK, VP, FM, $S P, J L, A T, H H, J K$, and JW. All authors read and approved the final manuscript.

\section{Funding}

This work was supported by the Dr. C.J. Vaillant Fund. The funders had no role in the design of the study; in the collection, analyses, or interpretation of data; in the writing of the manuscript, or in the decision to publish the results.

\section{Availability of data and material}

The datasets generated during and/or analysed during the current study are available from the corresponding author on reasonable request.

\section{Declarations}

\section{Ethics approval and consent to participate}

This study was performed in line with the principles of the 1964 Declaration of Helsinki. The study approved by the Medical Ethics Review Committee
Arnhem-Nijmegen (NL71550.091.19) at November 25, 2019. Informed consent was obtained from all subjects involved in the study.

\section{Consent for publication}

Not applicable.

\section{Competing interests}

The authors declare no conflicts of interest.

\section{Author details}

${ }^{1}$ Medical Ultrasound Imaging Center (MUSIC), Department of Medical Imaging/Radiology, Radboud Institute Health Sciences, Radboud University Medical Center, Geert Grooteplein Zuid 10,6525 GA Nijmegen, the Netherlands. ${ }^{2}$ Department of Radiation Oncology, Radboud University Medical Center, Nijmegen, the Netherlands. ${ }^{3}$ Department of Medical Psychology, Radboud University Medical Center, Nijmegen, the Netherlands. ${ }^{4}$ Donders Institute for Brain, Cognition and Behaviour, Centre for Cognition, Radboud University, Nijmegen, the Netherlands. ${ }^{5}$ Vincent Van Gogh Institute for Psychiatry, Venray, The Netherlands. ${ }^{6}$ Donders Institute for Brain, Cognition and Behaviour, Centre for Medical Neuroscience, Radboud University Medical Center, Nijmegen, the Netherlands. 'Department of Imaging/Radiology, Radboud University Medical Center, Nijmegen, the Netherlands. ${ }^{8}$ Center of Expertise for Cancer Survivorship, Radboud University Medical Center, Nijmegen, the Netherlands. ${ }^{9}$ Department of Neurology, Radboud University Medical Center, Nijmegen, the Netherlands.

Received: 8 September 2021 Accepted: 10 February 2022 Published online: 05 March 2022

\section{References}

1. Kaanders J, van den Bosch S, Dijkema T, Al-Mamgani A, Raaijmakers CPJ, Vogel WV. Advances in cancer imaging require renewed radiotherapy dose and target volume concepts. Radiother Oncol. 2020;148:140-2.

2. van den Bosch S, Doornaert PAH, Dijkema T, Zwijnenburg EM, Verhoef LCG, Hoeben BAW, et al. (18)F-FDG-PET/CT-based treatment planning for definitive (chemo)radiotherapy in patients with head and neck squamous cell carcinoma improves regional control and survival. Radiother Oncol. 2020;142:107-14.

3. Lacas B, Carmel A, Landais C, Wong SJ, Licitra L, Tobias JS, et al. Meta-analysis of chemotherapy in head and neck cancer (MACH-NC): An update on 107 randomized trials and 19805 patients, on behalf of MACH-NC group. Radiother Oncol. 2021;156:281-93.

4. Oeffinger KC, Mertens AC, Sklar CA, Kawashima T, Hudson MM, Meadows AT, et al. Chronic health conditions in adult survivors of childhood cancer. N Engl J Med. 2006;355(15):1572-82.

5. Suh E, Stratton KL, Leisenring WM, Nathan PC, Ford JS, Freyer DR, et al Late mortality and chronic health conditions in long-term survivors of early-adolescent and young adult cancers: a retrospective cohort analysis from the Childhood Cancer Survivor Study. Lancet Oncol. 2020;21(3):421-35.

6. McDougall GJ Jr, Oliver JS, Scogin F. Memory and cancer: a review of the literature. Arch Psychiatr Nurs. 2014;28(3):180-6.

7. Zer A, Pond GR, Razak ARA, Tirona K, Gan HK, Chen EX, et al. Association of Neurocognitive Deficits With Radiotherapy or Chemoradiotherapy for Patients With Head and Neck Cancer. JAMA Otolaryngol Head Neck Surg. 2018;144(1):71-9.

8. Bond SM, Dietrich MS, Gilbert J, Ely EW, Jackson JC, Murphy BA. Neurocognitive function in patients with head and neck cancer undergoing primary or adjuvant chemoradiation treatment. Support Care Cancer. 2016;24(10):4433-42.

9. Bolt S, Baylor C, Burns M, Eadie T. "I would have told you about being forgetful, but I forgot": the experience of cognitive changes and communicative participation after head and neck cancer. Disabil Rehabil. 2020:42(7):931-9.

10. Gan HK, Bernstein LJ, Brown J, Ringash J, Vakilha M, Wang L, et al. Cognitive Functioning After Radiotherapy or Chemoradiotherapy for Headand-Neck Cancer. Int J Radiat Oncol Biol Phys. 2011;81(1):126-34.

11. Hsiao K-Y, Yeh S-A, Chang C-C, Tsai P-C, Wu J-M, Gau J-S. Cognitive Function Before and After Intensity-Modulated Radiation Therapy in Patients 
With Nasopharyngeal Carcinoma: A Prospective Study. Int J Radiat Oncol Biol Phys. 2010;77(3):722-6.

12. Hua MS, Chen ST, Tang LM, Leung WM. Neuropsychological function in patients with nasopharyngeal carcinoma after radiotherapy. J Clin Exp Neuropsychol. 1998;20(5):684-93.

13. Lam Linda C. W, Leung S. F, Chan Y. L. Progress of Memory Function After Radiation Therapy in Patients With Nasopharyngeal Carcinoma. The Journal of Neuropsychiatry and Clinical Neurosciences. 2003;15(1):90-7.

14. Tang $Y$, Luo D, Rong $X$, Shi $X$, Peng Y. Psychological disorders, cognitive dysfunction and quality of life in nasopharyngeal carcinoma patients with radiation-induced brain injury. PLoS One. 2012;7:6 e36529.

15. Lee PW, Hung BK, Woo EK, Tai PT, Choi DT. Effects of radiation therapy on neuropsychological functioning in patients with nasopharyngeal carcinoma. J Neurol Neurosurg Psychiatry. 1989;52(4):488-92.

16. McDowell LJ, Ringash J, Xu W, Chan B, Lu L, Waldron J, et al. A cross sectional study in cognitive and neurobehavioral impairment in long-term nasopharyngeal cancer survivors treated with intensity-modulated radiotherapy. Radiother Oncol. 2019;131:179-85.

17. Wilbers J, Kappelle AC, Versteeg L, Tuladhar AM, Steens SCA, Meijer FJA, et al. Cognitive function, depression, fatigue and quality of life among long-term survivors of head and neck cancer. Neurooncol Pract. 2015;2(3):144-50.

18. McDowell L, Corry J, Ringash J, Rischin D. Quality of Life, Toxicity and Unmet Needs in Nasopharyngeal Cancer Survivors. Front Oncol. 2020;10:930.

19. Mo Y-L, Li L, Qin L, Zhu X-D, Qu S, Liang X, et al. Cognitive function, mood, and sleep quality in patients treated with intensity-modulated radiation therapy for nasopharyngeal cancer: A prospective study. Psycho-oncology. 2014;23(10):1185-91.

20. Anstey KJ, Mack HA, Cherbuin N. Alcohol consumption as a risk factor for dementia and cognitive decline: meta-analysis of prospective studies. Am J Geriatr Psychiatry. 2009;17(7):542-55.

21. Anstey KJ, von Sanden C, Salim A, O'Kearney R. Smoking as a risk factor for dementia and cognitive decline: a meta-analysis of prospective studies. Am J Epidemiol. 2007;166(4):367-78.

22. Ismail FY, Fatemi A, Johnston MV. Cerebral plasticity: Windows of opportunity in the developing brain. Eur J Paediatr Neurol. 2017:21(1):23-48

23. Dewar EO, Ahn C, Eraj S, Mahal BA, Sanford NN. Psychological distress and cognition among long-term survivors of adolescent and young adult cancer in the USA. J Cancer Surviv. 2021;15(5):776-84.

24. Panwar A, Batra R, Lydiatt WM, Ganti AK. Human papilloma virus positive oropharyngeal squamous cell carcinoma: A growing epidemic. Cancer Treat Rev. 2014;40(2):215-9.

25. Piepoli MF, Hoes AW, Agewall S, Albus C, Brotons C, Catapano AL, et al. 2016 European Guidelines on cardiovascular disease prevention in clinical practice: The Sixth Joint Task Force of the European Society of Cardiology and Other Societies on Cardiovascular Disease Prevention in Clinical Practice (constituted by representatives of 10 societies and by invited experts)Developed with the special contribution of the European Association for Cardiovascular Prevention \& Rehabilitation (EACPR). Eur Heart J. 2016;37(29):2315-81.

26. Verhage F. Intelligentie en leeftijd bij volwassenen en bejaarden. Groningen: Koninklijke Van Gorcum; 1964. 98 p.

27. Van der Elst W, van Boxtel MP, van Breukelen GJ, Jolles J. Rey's verbal learning test: normative data for 1855 healthy participants aged 24-81 years and the influence of age, sex, education, and mode of presentation. J Int Neuropsychol Soc. 2005;11(3):290-302.

28. Wechsler D. Wechsler Adult Intelligence Scale-3rd Edition (WAIS-III). San Antonio: TX: Harcourt Assessment; 1997.

29. Partington JE, Leiter RG. Partington's Pathways Test. Psychological Service Center Journal. 1949;1:11-20.

30. van den Berg E, Nys GM, Brands AM, Ruis C, van Zandvoort MJ, Kessels RP. The Brixton Spatial Anticipation Test as a test for executive function: validity in patient groups and norms for older adults. J Int Neuropsychol Soc. 2009;15(5):695-703.

31. Houx PJ, Jolles J, Vreeling FW. Stroop interference: aging effects assessed with the Stroop Color-Word Test. Exp Aging Res. 1993;19(3):209-24.
32. Schmand B, Groenink SC, van den Dungen M. Letter fluency: psychometric properties and Dutch normative data. Tijdschr Gerontol Geriatr. 2008;39(2):64-76.

33. Schaapsmeerders P, Maaijwee NA, van Dijk EJ, Rutten-Jacobs LC, Arntz $\mathrm{RM}$, Schoonderwaldt $\mathrm{HC}$, et al. Long-term cognitive impairment after first-ever ischemic stroke in young adults. Stroke. 2013;44(6):1621-8.

34. Recklitis CJ, Blackmon JE, Chang G. Validity of the Brief Symptom Inventory-18 (BSI-18) for identifying depression and anxiety in young adult cancer survivors: Comparison with a Structured Clinical Diagnostic Interview. Psychol Assess. 2017;29(10):1189-200.

35. Custers JAE, van den Berg SW, van Laarhoven HWM, Bleiker EMA, Gielissen MFM, Prins JB. The Cancer Worry Scale: Detecting Fear of Recurrence in Breast Cancer Survivors. Cancer Nurs. 2014;37(1):E44-50.

36. Ponds R, Boxtel M, Jolles J. De "Cognitive Failure Questionnaire" als maat voor subjectief cognitief functioneren. Tijdschrift voor Neuropsychologie. 2006; $1: 37-45$

37. Zigmond AS, Snaith RP. The hospital anxiety and depression scale. Acta Psychiatr Scand. 1983;67(6):361-70.

38. Vercoulen JHMM, Swanink CMA, Fennis JFM, Galama JMD, Vandermeer JWM, Bleijenberg G. Dimensional Assessment of Chronic Fatigue Syndrome. J Psychosom Res. 1994;38(5):383-92.

39. Worm-Smeitink M, Gielissen M, Bloot L, van Laarhoven HWM, van Engelen BGM, van Riel P, et al. The assessment of fatigue: Psychometric qualities and norms for the Checklist individual strength. J Psychosom Res. 2017;98:40-6.

40. van der Ploeg E, Mooren TT, Kleber RJ, van der Velden PG, Brom D. Construct validation of the Dutch version of the impact of event scale. Psychol Assess. 2004;16(1):16-26.

41. Rinkel RN, Leeuw IMVD, van Reij EJ, Aaronson NK, Leemans CR. Speech handicap index in patients with oral and pharyngeal cancer: Better understanding of patients' complaints. Head and Neck-Journal for the Sciences and Specialties of the Head and Neck. 2008;30(7):868-74.

42. van de Poll-Franse LV, Mols F, Gundy CM, Creutzberg CL, Nout RA, Verdonck-de Leeuw IM, et al. Normative data for the EORTC QLQ-C30 and EORTC-sexuality items in the general Dutch population. Eur J Cancer. 2011:47(5):667-75.

43. Fazekas F, Chawluk JB, Alavi A, Hurtig HI, Zimmerman RA. MR signal abnormalities at 1.5 T in Alzheimer's dementia and normal aging. Am J Roentgenol. 1987;149(2):351-6.

44. Wardlaw JM, Smith EE, Biessels GJ, Cordonnier C, Fazekas F, Frayne R, et al. Neuroimaging standards for research into small vessel disease and its contribution to ageing and neurodegeneration. The Lancet Neurology. 2013;12(8):822-38.

45. Smith SM. Fast robust automated brain extraction. Hum Brain Mapp. 2002;17(3):143-55.

46. Zhang YY, Brady M, Smith S. Segmentation of brain MR images through a hidden Markov random field model and the expectation-maximization algorithm. IEEE Trans Med Imaging. 2001;20(1):45-57.

47. van der Holst HM, Tuladhar AM, van Norden AGW, de Laat KF, van Uden IWM, van Oudheusden $\perp B$, et al. Microstructural integrity of the cingulum is related to verbal memory performance in elderly with cerebral small vessel disease: The RUN DMC study. Neuroimage. 2013;65:416-23.

48. Lezak MD, Howieson DB, Bigler ED, Tranel D. Neuropsychological assessment, 5th ed. New York, NY, US: Oxford University Press; 2012. xxv, 1161$x x v, p$.

49. Benjamini Y, Hochberg Y. Controlling the False Discovery Rate - a Practical and Powerful Approach to Multiple Testing. Journal of the Royal Statistical Society Series B-Statistical Methodology. 1995;57(1):289-300.

50. Dregan A, Stewart R, Gulliford MC. Cardiovascular risk factors and cognitive decline in adults aged 50 and over: a population-based cohort study. Age Ageing. 2013;42(3):338-45

51. Ahles TA, Root JC, Ryan EL. Cancer- and cancer treatment-associated cognitive change: an update on the state of the science. J Clin Oncol. 2012;30(30):3675-86.

52. Jim HSL, Jennewein SL, Quinn GP, Reed DR, Small BJ. Cognition in Adolescent and Young Adults Diagnosed With Cancer: An Understudied Problem. J Clin Oncol. 2018;36(27):2752-4.

53. Stern Y. Cognitive reserve. Neuropsychologia. 2009;47(10):2015-28.

54. Dorresteijn LD, Kappelle AC, Boogerd W, Klokman WJ, Balm AJ, Keus RB, et al. Increased risk of ischemic stroke after radiotherapy on the neck in patients younger than 60 years. J Clin Oncol. 2002;20(1):282-8. 
55. Gujral DM, Chahal N, Senior R, Harrington KJ, Nutting CM. Radiationinduced carotid artery atherosclerosis. Radiother Oncol. 2014;110(1):31-8.

56. Wilbers J, Dorresteijn LD, Haast R, Hoebers FJ, Kaanders JH, Boogerd W, et al. Progression of carotid intima media thickness after radiotherapy: a long-term prospective cohort study. Radiother Oncol. 2014;113(3):359-63.

57. Plummer C, Henderson RD, O'Sullivan JD, Read SJ. Ischemic Stroke and Transient Ischemic Attack After Head and Neck Radiotherapy A Review. Stroke. 2011;42(9):2410-8.

58. Debette S, Markus HS. The clinical importance of white matter hyperintensities on brain magnetic resonance imaging: systematic review and meta-analysis. BMJ. 2010;341:c3666.

59. Williams AM, Lindholm J, Siddiqui F, Ghanem TA, Chang SS. Clinical Assessment of Cognitive Function in Patients with Head and Neck Cancer: Prevalence and Correlates. Otolaryngology-Head and Neck Surgery. 2017;157(5):808-15.

60. Piai V, Prins JB, Verdonck-de Leeuw IM, Leemans CR, Terhaard CHJ, Langendijk JA, et al. Assessment of Neurocognitive Impairment and Speech Functioning Before Head and Neck Cancer Treatment. JAMA Otolaryngol Head Neck Surg. 2019;145(3):251-7.

61. Bøhn S-KH, Thorsen L, Kiserud CE, Fosså SD, Lie HC, Loge JH, et al. Chronic fatigue and associated factors among long-term survivors of cancers in young adulthood. Acta Oncologica. 2019;58(5):753-62.

62. Stone P, Richardson A, Ream E, Smith AG, Kerr DJ, Kearney N. Cancerrelated fatigue: Inevitable, unimportant and untreatable? Results of a multi-centre patient survey. Ann Oncol. 2000;11(8):971-6.

63. Curt GA, Breitbart W, Cella D, Groopman JE, Horning SJ, Itri LM, et al. Impact of cancer-related fatigue on the lives of patients: new findings from the Fatigue Coalition. Oncologist. 2000;5(5):353-60.

64. Nguyen N-TA, Ringash J. Head and Neck Cancer Survivorship Care: A Review of the Current Guidelines and Remaining Unmet Needs. Current Treatment Options in Oncology. 2018;19(8):44.

65. Pignon JP, le Maitre A, Maillard E, Bourhis J. Group M-NC. Meta-analysis of chemotherapy in head and neck cancer (MACH-NC): an update on 93 randomised trials and 17,346 patients. Radiother Oncol. 2009:92(1):4-14

66. Koch $L$, Jansen $L$, Brenner $H$, Arndt $V$. Fear of recurrence and disease progression in long-term ( $\geq 5$ years) cancer survivors - a systematic review of quantitative studies. Psychooncology. 2013;22(1):1-11.

67. Simard S, Thewes B, Humphris G, Dixon M, Hayden C, Mireskandari S, et al. Fear of cancer recurrence in adult cancer survivors: a systematic review of quantitative studies. J Cancer Surviv. 2013;7(3):300-22.

68. Custers JA, Tielen R, Prins JB, de Wilt JH, Gielissen MF, van der GraafWT. Fear of progression in patients with gastrointestinal stromal tumors (GIST): Is extended lifetime related to the Sword of Damocles? Acta Oncol. 2015;54(8):1202-8.

69. Custers JAE, Gielissen MFM, Janssen SHV, de Wilt JHW, Prins JB. Fear of cancer recurrence in colorectal cancer survivors. Support Care Cancer 2016;24(2):555-62.

70. van de Wal M, van Oort I, Schouten J, Thewes B, Gielissen M, Prins J. Fear of cancer recurrence in prostate cancer survivors. Acta Oncol. 2016;55(7):821-7.

71. Dang J, King KM, Inzlicht M. Why Are Self-Report and Behavioral Measures Weakly Correlated? Trends Cogn Sci. 2020;24(4):267-9.

72. Konen T, Karbach J. Self-Reported Cognitive Failures in Everyday Life: A Closer Look at Their Relation to Personality and Cognitive Performance. Assessment. 2020;27(5):982-95.

73. Abel E, Silander E, Nyman J, Björk-Eriksson T, Hammerlid E. Long-Term Aspects of Quality of Life in Head and Neck Cancer Patients Treated With Intensity Modulated Radiation Therapy: A 5-Year Longitudinal Follow-up and Comparison with a Normal Population Cohort. Adv Radiat Oncol. 2020;5(1):101-10.

74. Chen AM, Daly ME, Farwell DG, Vazquez E, Courquin J, Lau DH, et al. Quality of life among long-term survivors of head and neck cancer treated by intensity-modulated radiotherapy. JAMA Otolaryngol Head Neck Surg. 2014;140(2):129-33.

75. Heijnen BJ, Speyer R, Kertscher B, Cordier R, Koetsenruijter KWJ, Swan K, et al. Dysphagia, Speech, Voice, and Trismus following Radiotherapy and/ or Chemotherapy in Patients with Head and Neck Carcinoma: Review of the Literature. BioMed Res Int. 2016;2016:6086894.
76. Schwartz CE, Sprangers MA. Methodological approaches for assessing response shift in longitudinal health-related quality-of-life research. Soc Sci Med. 1999;48(11):1531-48

77. Bernstein LJ, McCreath GA, Komeylian Z, Rich JB. Cognitive impairment in breast cancer survivors treated with chemotherapy depends on control group type and cognitive domains assessed: A multilevel meta-analysis. Neurosci Biobehav Rev. 2017;83:417-28.

78. Piai V, Jansen F, Dahlslätt K, Verdonck-de Leeuw IM, Prins J, Leemans R, et al. Prevalence of neurocognitive and perceived speech deficits in patients with head and neck cancer before treatment: Associations with demographic, behavioral, and disease-related factors. Head \& Neck. 2021;n/a(n/a).

79. Sinha P, Wong AWK, Kallogjeri D, Piccirillo JF. Baseline Cognition Assessment Among Patients With Oropharyngeal Cancer Using PROMIS and NIH Toolbox. JAMA Otolaryngology-Head \& Neck Surgery. 2018;144(11):978-87.

80. Pasi M, van Uden IWM, Tuladhar AM, de Leeuw F-E, Pantoni L. White Matter Microstructural Damage on Diffusion Tensor Imaging in Cerebral Small Vessel Disease. Stroke. 2016;47(6):1679-84.

81. Nitkunan A, Barrick TR, Charlton RA, Clark CA, Markus HS. Multimodal $M R I$ in cerebral small vessel disease: its relationship with cognition and sensitivity to change over time. Stroke. 2008;39(7):1999-2005.

\section{Publisher's Note}

Springer Nature remains neutral with regard to jurisdictional claims in published maps and institutional affiliations.

Ready to submit your research? Choose BMC and benefit from:

- fast, convenient online submission

- thorough peer review by experienced researchers in your field

- rapid publication on acceptance

- support for research data, including large and complex data types

- gold Open Access which fosters wider collaboration and increased citations

- maximum visibility for your research: over $100 \mathrm{M}$ website views per year

At BMC, research is always in progress.

Learn more biomedcentral.com/submissions 